\title{
Physical and psychosocial work environmental risk factors of low-back pain: protocol for a 1 year prospective cohort study
}

Rúni Bláfoss ${ }^{1,2^{*}}$ (D) Per Aagaard ${ }^{2}$ and Lars Louis Andersen ${ }^{1,3}$

\begin{abstract}
Background: Musculoskeletal disorders, and in particular low-back pain (LBP), are common among blue collar workers. In the work environment, both physical- and psychosocial risk factors exist. Working in warehouses in Denmark involve large quantities of occupational lifting, high work pace and a low degree of influence at work. This study investigates both acute and long-term associations between physical- and psychosocial work environmental factors and risk of LBP in warehouse workers. The specific study aims are to investigate 1) exposure-response associations between quantity of occupational lifting and short-term (day-to-day) changes in LBP, 2) the influence of accumulated workdays and rest days during a working week on LBP, 3) long-term association between occupational lifting exposure and LBP when assessed over 1 year, and 4) the role of psychological and social factors on the above associations.
\end{abstract}

Methods: The present study is designed as a 1-year prospective cohort study that will examine full-time warehouse workers from up to five retail chains in Denmark. Study aims 1 and 2 will be addressed using objective data based on company records with information on weight of all the goods handled by each warehouse worker during every single workday for 3 weeks. During this period, each worker will reply to text messages received before and after every workday (also on days off work) in which study participants will score their pain in the low back, bodily fatigue and perceived mental stress (scale 0-10). Long-term pain development is assessed using questionnaire surveys before and after 1 year. Further, pressure pain threshold (PPT) will be measured for selected trunk extensor muscles in approximately 50 workers using algometry along with measurements of maximal trunk extensor strength. Associations are modelled using linear mixed models with repeated measures between variables and LBP controlled for relevant confounders.

(Continued on next page)

\footnotetext{
* Correspondence: rub@nfa.dk

'Musculoskeletal Disorders and Physical Workload, National Research Centre for the Working Environment, Lersø Parkalle 105, DK-2100 Copenhagen, Denmark

${ }^{2}$ Department of Sports Science and Clinical Biomechanics, Research Unit for Muscle Physiology and Biomechanics, University of Southern Denmark, DK-5000 Odense, Denmark

Full list of author information is available at the end of the article
}

(c) The Author(s). 2019 Open Access This article is distributed under the terms of the Creative Commons Attribution 4.0 International License (http://creativecommons.org/licenses/by/4.0/) which permits unrestricted use, distribution, and reproduction in any medium, provided you give appropriate credit to the original author(s) and the source, provide a link to the Creative Commons license, and indicate if changes were made. The Creative Commons Public Domain Dedication waiver (http://creativecommons.org/publicdomain/zero/1.0/) applies to the data made available in this article, unless otherwise stated. 
(Continued from previous page)

Discussion: This study provides knowledge about the acute and long-term associations between physicaland psychosocial work environmental factors and LBP. The obtained data will have the potential to provide recommendations on improved design of the working week to minimize the risk of LBP among warehouse workers, and may potentially enable to identify a reasonable maximum lifting threshold per day (ton lifted/ day).

Keywords: Musculoskeletal diseases, Musculoskeletal pain, Pain threshold, Workload, Occupational stress, Workplace, Psychology, Sociological factors

\section{Background}

Musculoskeletal disorders are the leading cause of physical disability and a major burden on individuals and societies, with low-back pain (LBP) representing the most frequent musculoskeletal disorder [1-3]. Workers exposed to regular occupational lifting are in elevated risk of LBP [4-7] while additionally characterized by an increased risk of long-term sickness absence, early retirement and earlier death [8-13].

Warehouse workers represent a job category with physically demanding job tasks that comprise large amounts of occupational lifting [14, 15]. In the 2018 Work Environment \& Health study, warehouse- and transport workers in Denmark rated their job to be physically demanding with a mean score of 5.4 on a 0-10 scale [14]. The Work Environment \& Health study evaluates both physical and psychosocial work environmental factors and overall health in a range of job types, with the latest survey including 38,000 respondents from the general working population in Denmark [14]. Besides rating their work as physically demanding, $36 \%$ of the warehouse- and transport workers reported musculoskeletal pain several times per week while $7 \%$ reported a limited work capacity due to pain [14]. Moreover, warehouse- and transport workers estimated that loads of $16 \mathrm{~kg}$ or more were lifted for about $26 \%$ of the workday. Thus, warehouse- and transport workers in Denmark are highly exposed to heavy occupational lifting, which per se is known to increase the risks of developing LBP [4-6, $16,17]$. Likewise, isolated warehouse work consists of both heavy and frequent lifting [14, 15]. Based on meta-analysis of the available literature, Coenen and co-workers investigated the influence of occupational lifting on the occurrence of LBP by quantifying duration, frequency and intensity of the lifting [6]. The study found odds ratios for LBP to be 1.11 per $10 \mathrm{~kg}$ lifted and 1.09 per 10 lifts per day [6]. In relation to this, Danish warehouse- and transport workers estimated their lifting burdens to be $16 \mathrm{~kg}$ or more for $26 \%$ of the workday [14]. Based on these odds ratios, Danish warehouse- and transport workers are exposed to heavy daily lifting loads ( $\geq 16 \mathrm{~kg}$ for $26 \%$ of the day) that may be expected to result in an elevated risk of LBP and related musculoskeletal disorders.

Musculoskeletal disorders, including LBP, are influenced not only by physical work factors, but also psychosocial work environmental factors, e.g. low job control and low social support [5, 17, 18]. Notably, Danish warehouse- and transport workers are scoring low on psychosocial work environmental factors [14], suggesting that Danish warehouse- and transport workers are exposed to a physically demanding job that typically comprise a poor psychosocial working environment.

Previous studies investigating risk factors for reduced health among workers with physically demanding job tasks typically have involved subjective measurements [5, $8-10,19,20]$. However, a recent study among full-time

\section{Daily registration for 3 weeks: \\ Text messages \\ Company records \\ Physiological measurements}

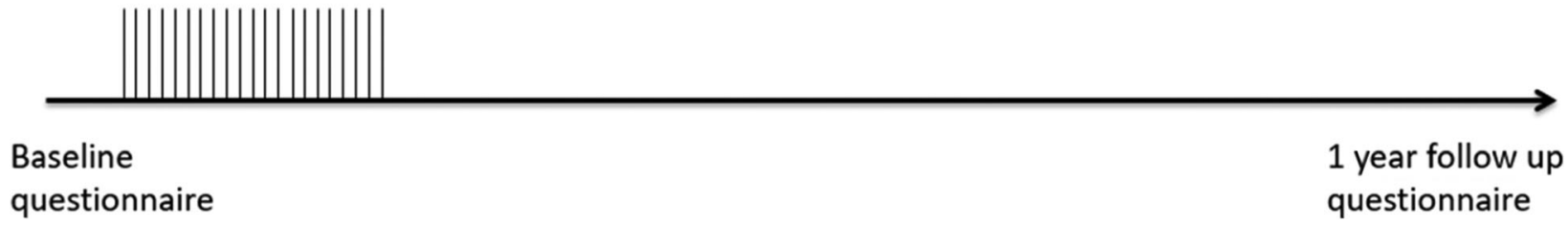

Fig. 1 Time line of the study 


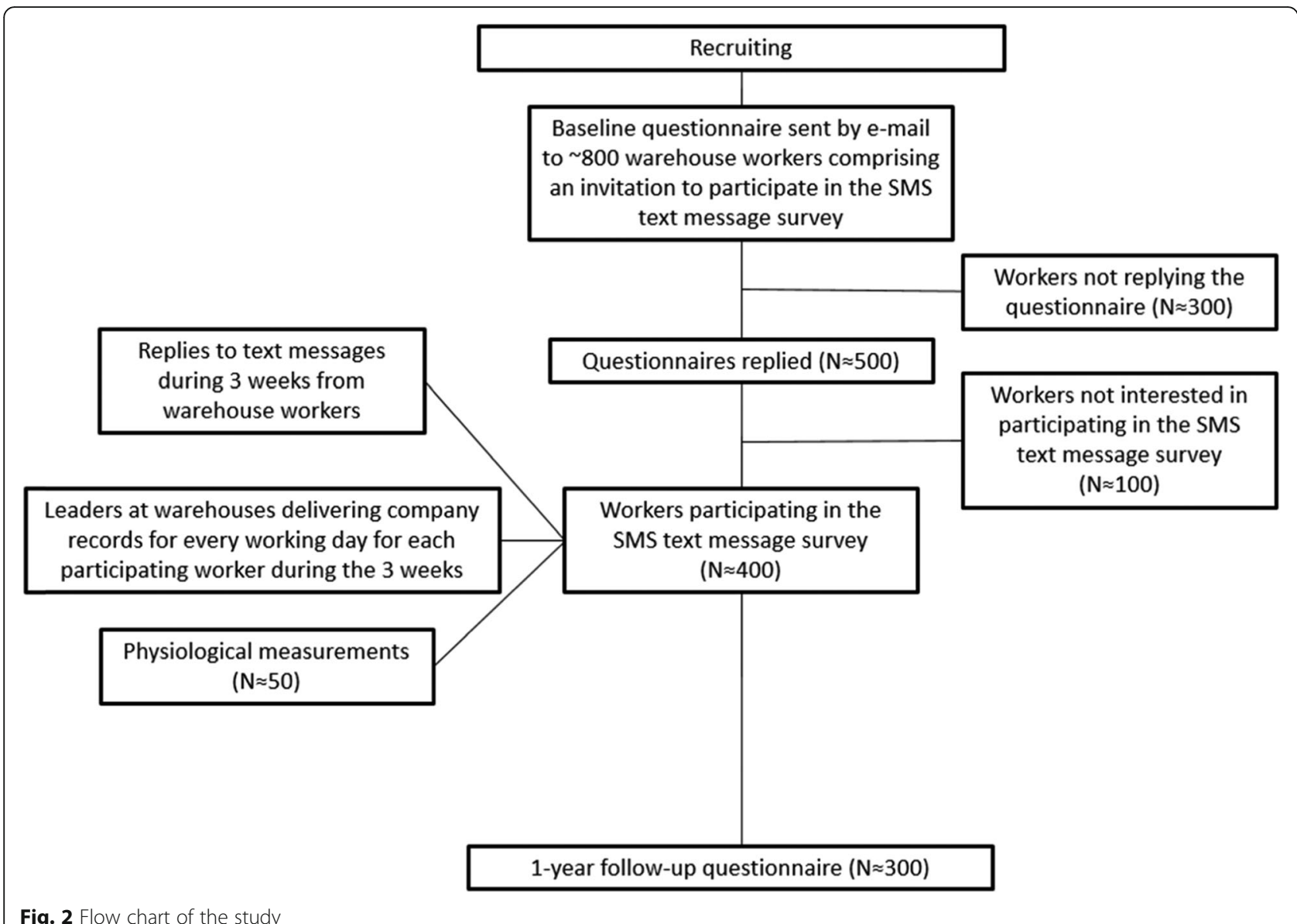

supermarket workers investigated the association between occupational lifting and day-to-day variations in LBP [21]. Using internal company records to quantify the daily lifting volume and daily text message communication to assess pain intensity in the low back in 3 weeks, an exposure-response association was observed between workload intensity and LBP intensity, along with higher pain intensity the morning after workdays [21].

The aim of the present study, therefore, is to investigate the association between objectively assessed occupational lifting and perceived psychosocial work environmental factors and LBP intensity among warehouse workers in retail industry warehouses in Denmark. The objectives of the study is to investigate: 1) the exposure-response association between quantity of occupational lifting and short-term (day-to-day) changes in LBP, 2) the influence of accumulated workdays and rest days during a working week on LBP, 3) long-term association between occupational lifting exposure and LBP when assessed over 1 year, and 4) the role of psychological and social work environmental factors on the above associations. Our hypotheses is that higher total lifting loads will associate with more intense LBP, that LBP intensity increases during consecutive workdays and is higher at 1-year follow-up, and that these associations comprise psychological and social factors.

\section{Methods}

\section{Study design and population}

The present 1-year prospective cohort study investigates work-related symptoms among warehouse workers from up to five different retail chains industry warehouses in Denmark. Enrolled study participants will in FebruaryMarch 2020 receive a baseline questionnaire by e-mail that will address various aspects of physical-, psychological and social work environment and health. The questionnaire will also comprise an invitation to participate in a text message survey. Participants recruited for the text message survey will receive a SMS text message before and after every workday for 3 full weeks (21 days) during March-April 2020 to rate the magnitude of pain in their low back, and to score their current level of perceived physical fatigue and mental stress. During the same 3-week study period, section leaders at the warehouses will provide company records about the workload of each participating warehouse worker (goods handled by each worker, weight of the goods) along with a working schedule for each worker. Additionally, during 
the same period, pressure pain threshold (PPT) will be measured in about 50 workers along with an optional assessment of maximal isometric trunk extensor strength (MVC) and systemic resting blood pressure. One year after responding to the baseline questionnaire, the participant will be receiving a follow-up questionnaire in FebruaryMarch 2021 that will evaluate the physical-, psychological and social work factors and health aspects assessed 1 year previously. Fig. 1 illustrates a time line of the study.

Inclusion criteria for the warehouse workers recruited for this study are: working $\geq 30 \mathrm{~h}$ per week in a registered retail industry warehouse, ability to read and understand Danish or English, $\geq 18$ years of age.

\section{Ethical aspects}

According to Danish legislation, scientific questionnaire studies are not required to attain approval by official Danish ethical or scientific committees nor to obtain informed consent from study participants. Nevertheless, all questionnaires and text messages will be handled anonymously. A data manager at the research centre will store the data on a secure drive and de-identify the data before the researcher get access to these. All physiological measurements (PPT, MVC, systemic blood pressure) have been approved by The Danish National Committee on Biomedical Research Ethics (journal number: H-3-2010-062), and the project is registered at the Danish Data Protection Agency and ClinicalTrials.gov (NCT04240184). Prior to giving their informed consent, all participants participating in the physiological measurements will be informed orally and in writing about the objectives and content of the study, as well as of their rights and potential risks of the study in accordance with the Helsinki Declaration.

\section{Baseline and follow-up questionnaires}

The baseline and follow-up questionnaires contain questions about basic characteristics, general health and physical-, psychological and social work environmental factors. Questions about the physical work environment are based on previous investigations from our lab and the Work Environment \& Health study [14, 21]. Questions pertaining the psychosocial working environment are selected from The Danish Psychosocial Work Environment Questionnaire (DPQ) [22] while questions about fear avoidance beliefs are selected from the FearAvoidance Beliefs Questionnaire [23]. The questionnaires will be sent by e-mail from a web-based survey platform (SurveyXact) while containing a web-link directed to the electronic questionnaire.

\section{Text message survey}

All study participants will receive and reply to twicedaily SMS text messages before and after the workday for 21 consecutive days (also on days off work) [21]. The messages will be sent from a web-based survey platform (SurveyXact) containing a web-link that directs the participant to a 3-question survey about pain in low back, perceived physical fatigue and mental stress. To reply, participants choose a number between 0 and 10, where 0 is best and 10 is worst.

\section{Company records}

During the 3-week observation period, warehouse section leaders will provide company records for all participants in the text message survey. These records will provide information on the specific goods handled (type and weight) manually by each participant during each single workday (workload), supplemented by a specific working schedule for each participant [21]. Based on these data the total weight lifted by each participant per workday for all 3 weeks will be calculated. Additionally, the repetitive lifting pattern of the different goods can be estimated from the amounts of each type of good and information about the total work duration, altogether allowing to quantify the duration, frequency and intensity of the physical work performed by each participant.

\section{Pain pressure threshold}

During the 3-week observation period, PPT in the lowback muscles ( $m$. erector spinae longissimus) is measured using an electronic pressure algometer (Somedic Productions AB, Sollentuna, Sweden, Europe) on approximately 50 participants for 2 days per week, i.e. comprising 6 measurement days in total. Control measurements will be conducted in a lower limb muscle ( $\mathrm{m}$. tibialis anterior) that is not directly affected by the manual lifting. The first PPT measurement is performed by the beginning of a working day preceded by a day off from work, while another PPT measurement is conducted during the working week just prior to initiating the fourth consecutive working day. PPT measurements are performed with a circular probe with a contact area of $1 \mathrm{~cm}^{2}$ at 3 contact sites on the $\mathrm{m}$. erector spinae longissimus muscles on each side of the spine, and each contact area is measured 3 times with an interval time of $1 \frac{1 / 2}{2}$ minute [24, 25]. The test leader presses the algometer against the back muscles and slowly increases the pressure. Participants are informed to press a button on a pinch handle mounted to the algometer when the pressure changes from the feeling of pressure to the feeling of pain $[24,25]$. The display of the pressure algometer will not be visual to the participants during the measurements. The PPT is expressed as the average value of the 3 measurements. All PPT measurements will be performed by the same test leader. Previous studies have found PPT both valid and a test-retest reliability level of satisfactory to good [26-31]. 


\section{Maximal isometric muscle strength}

Participants in which PPT is determined will also be offered (encouraged) to have maximal voluntary contraction strength of the trunk extensors (MVC) assessed. Subsequent to the recording of PPT, MVC measurements are conducted at a working day preceded by a day off from work. Systemic blood pressure is measured prior to the MVC test and participants with blood pressure exceeding $160 / 100 \mathrm{mmHg}$ will be excluded from testing [24, 32-34]. MVC measurements are performed using a standardized MVC procedure in a standing testposition in a custom-built device [34]. With a strap fixed around the shoulders, the back slightly flexed and leaning towards a pillow at the height of the anterior iliac spine, the participant will be informed to extend the back [34]. A warm-up trial consisting of 3 submaximal contraction efforts will be performed followed by 3 maximal MVC efforts separated by 1 min rest interval. Participants will be informed to slowly build up the contraction force to reach their maximum capacity after 2$3 \mathrm{~s}$, and to continue the contraction until the test leader tells them to stop (approximately $3 \mathrm{~s}$ ). Verbal encouragement will be provided throughout the test. The maximal isometric muscle strength will be expressed as the peak force produced during the $3 \mathrm{MVC}$ trials.

\section{Statistical analysis}

The baseline questionnaire will be sent out to $\sim 800$ warehouse workers (see Fig. 2 for flow chart illustration). Based on a previous study performed by our lab [21], we expect a participation and response rate of $>50 \%$ in the SMS text message survey, i.e. $N \approx 400$. The section leaders at the warehouses have informed of a yearly worker turnover rate of $\sim 14 \%$ in the different retail chains. Thus, when taken other factors into account, a drop-out rate of $20-30 \%$ is expected at the 1-year follow up, i.e. $\mathrm{N} \approx 300$. In 2017, Andersen \& co-workers found significant day-to-day differences in LBP among 95 supermarket workers [21]. The sample size of the present study is therefore sufficient to investigate associations between risk factors at work and LBP.

The statistical analyses are based on methods previously published by our lab [21]. In brief, the statistical analysis will be based on linear mixed models with repeated measures (Proc Mixed, SAS version 9.4, SAS Institute, Cary, NC). LBP is the main outcome variable of the study and will be analysed as a continuous variable. PPT is a supplementary outcome and likewise treated as a continuous variable. Warehouses are entered as a random factor to account for clustering between work sites. Participant is entered as repeated factor using an autoregressive covariance structure. The estimation model is restricted maximum likelihood with degrees of freedom based on Satterthwaite approximation. The explanatory variables (fixed factors) for the first 3 objectives are 1) $\mathrm{kg}$ lifted per working day, 2) combination of working days and days off from work, and 3) mean of daily lifting $(\mathrm{kg} /$ day) during the 3 baseline weeks in relation to the change in LBP at 1-year follow-up. Analyses will be adjusted for relevant confounders as age, gender and psychosocial work environmental factors. For the fourth research question, the estimates of psychosocial variables will be drawn out of analyses 1-3, and we will also test whether the psychosocial factors interacts with the physical workload in relation to the change in LBP. Results are reported as least square mean differences with 95\% confidence intervals (95\% CI). An alpha-level below 0.05 is considered statistically significant.

\section{Discussion}

The present cohort study will be the first to investigate acute- and long-term associations between physical and psychosocial work environmental factors and LBP among retail industry warehouse workers. The study will provide valuable knowledge about the risk of LBP and the day-to-day and weekly variations in pain intensity, while also investigating the development in LBP during a 1-year observation period in Danish retail industry warehouse workers. The obtained results potentially provide a basis to establish an improved design of the daily and weekly work load distribution pattern among warehouse workers, and may potentially allow to identify a maximum lifting threshold per day effective of reducing the risk of LBP in this large occupational group of workers.

\section{Strengths and limitations}

A methodological strength of the present study is the objective quantification of individual day-to-day workload based on company records. These records provide precise data on the weight and quantity of each good handled by each employee. By contrast, the majority of previous research is based on self-reports of ergonomic exposures. Moreover, the repeated measure design of the 3-week text message period strengthens the study by eliminating recall bias. Another strength is the 1-year follow-up assessments, which provides knowledge about the long-term effects of occupational lifting not revealed by the acute day-to-day or weekly effects observed during the initial 3-week observation period. Furthermore, it is a methodological strength of the study that objective PPT measurements are combined with self-reported subjective pain scores. Finally, the present measurement of maximal trunk extensor strength enables to investigate the potential association between LBP and regional musculoskeletal function. These data may provide important knowledge about the influence of adequate physical capacity on prevention of LBP in physically demanding job settings. 
A number of potential study limitations may also be listed. Firstly, the present study does not provide data on the specific biomechanical exposure during work, i.e. does not consider if the workers are working with back bent or twisted, arms above shoulder height etc., which are factors known to increase the risk of musculoskeletal injury independently of the magnitude of load lifted $[5,8]$. However, it is plausible that these factors will be quite equal between different workers, as they all handle goods at a warehouse. Secondly, the company records provide precise information about the weight and number of goods handled by each worker, but it does not tell the magnitude of the horizontal and vertical displacement distances the worker is handling the goods. However, this factor is also likely to be quite equal between the workers of the present study. Thus, while the results may be generalizable to manual material handling of goods similar to that in a warehouse, the results in terms of a safe lifting threshold may not be generalizable to all types of bluecollar workers.

\section{Abbreviations}

LBP: Low-back pain; MVC: Maximal voluntary contraction strength of the trunk extensors; PPT: Pressure pain threshold

\section{Acknowledgments}

Not applicable.

\begin{abstract}
Authors' contributions
LLA had the original idea for the study and obtained the funding. RB, PA and LLA discussed the specific design and content of the study, while LLA and RB finished the design and RB developed the questionnaire surveys with assistance from LLA. RB recruited participants and performed the study. RB wrote the draft of the manuscript before PA and LLA critically read and reviewed the manuscript. Thus, all authors have read and approved the manuscript.
\end{abstract}

\section{Funding}

The research project is funded by the Danish Working Environment Research Fund (Arbejdsmiljøforskningsfonden), grant number 20185100786.

\section{Availability of data and materials}

Researchers interested in collaborating using the data from the study should contact the corresponding author and senior author.

\section{Ethics approval and consent to participate}

According to Danish legislation, scientific questionnaire studies are not required to attain approval by official Danish ethical or scientific committees nor to obtain informed consent from study participants. Nevertheless, all questionnaires and text messages will be handled anonymously. A data manager at the research centre will store the data on a secure drive and deidentify the data before the researcher get access to these. All physiological measurements (pressure pain threshold, maximal trunk extensor strength, systemic blood pressure) have been approved by The Danish National Committee on Biomedical Research Ethics (journal number: H-3-2010-062), and the project is registered at the Danish Data Protection Agency. Prior to giving their informed consent, all participants participating in the physiological measurements will be informed orally and in writing about the objectives and content of the study, as well as of their rights and potential risks of the study in accordance with the Helsinki Declaration.

\section{Consent for publication}

Not applicable.

\section{Competing interests}

The authors declare that they have no competing interests.

\section{Author details}

${ }^{1}$ Musculoskeletal Disorders and Physical Workload, National Research Centre for the Working Environment, Lersø Parkalle 105, DK-2100 Copenhagen, Denmark. ${ }^{2}$ Department of Sports Science and Clinical Biomechanics, Research Unit for Muscle Physiology and Biomechanics, University of Southern Denmark, DK-5000 Odense, Denmark. ${ }^{3}$ Sport Sciences, Department of Health Science and Technology, Aalborg University, DK-9100 Aalborg, Denmark.

Received: 22 October 2019 Accepted: 9 December 2019

Published online: 27 December 2019

References

1. Woolf AD, Pfleger B. Burden of major musculoskeletal conditions. Bull World Health Organ. 2003;81(9):646-56.

2. European Agency for Safety and Health at Work, editor. OSH in figures: work-related musculoskeletal disorders in the EU - Facts and figures. Luxembourg: Office for Official Publ. of the Europ. Communities; 2010. p. 179 s. (European risk observatory report)

3. Weinstein SL. The Burden of Musculoskeletal Conditions. J Bone Joint Surg Am. 2016;98(16):1331.

4. Kuiper JI, Burdorf A, Verbeek JHAM, Frings-Dresen MHW, van der Beek AJ, Viikari-Juntura ERA. Epidemiologic evidence on manual materials handling as a risk factor for back disorders:a systematic review. Int J Ind Ergon. 1999; 24(4):389-404.

5. da Costa BR, Vieira ER. Risk factors for work-related musculoskeletal disorders: a systematic review of recent longitudinal studies. Am J Ind Med. 2010;53(3):285-323.

6. Coenen P, Gouttebarge V, van der Burght ASAM, van Dieën JH, FringsDresen MHW, van der Beek AJ, Burdorf A. The effect of lifting during work on low back pain: a health impact assessment based on a meta-analysis. Occup Environ Med. 2014;71(12):871-7.

7. Heuch I, Heuch I, Hagen K, Zwart J-A. Physical activity level at work and risk of chronic low back pain: a follow-up in the Nord-Trøndelag health study. PLoS One. 2017;12(4):e0175086.

8. Lund T, Labriola M, Christensen KB, Bültmann U, Villadsen E. Physical work environment risk factors for long term sickness absence: prospective findings among a cohort of 5357 employees in Denmark. BMJ. 2006; 332(7539):449-52.

9. Sterud T. Work-related mechanical risk factors for long-term sick leave: a prospective study of the general working population in Norway. Eur $J$ Public Health. 2014;24(1):111-6.

10. Andersen LL, Fallentin N, Thorsen SV, Holtermann A. Physical workload and risk of long-term sickness absence in the general working population and among blue-collar workers: prospective cohort study with register followup. Occup Environ Med. 2016;73(4):246-53.

11. Sundstrup E, Hansen ÅM, Mortensen EL, Poulsen OM, Clausen T, Rugulies R, et al. Retrospectively assessed physical work environment during working life and risk of sickness absence and labour market exit among older workers. Occup Environ Med. 2018;75(2):114-23.

12. Coenen P, Huysmans MA, Holtermann A, Krause N, van Mechelen W, Straker LM, et al. Do highly physically active workers die early? A systematic review with meta-analysis of data from 193696 participants. Br J Sports Med. 2018; 52(20):1320-6.

13. Lallukka T, Kaila-Kangas L, Mänty M, Koskinen S, Haukka E, Kausto J, et al. Work-Related Exposures and Sickness Absence Trajectories: A Nationally Representative Follow-up Study among Finnish Working-Aged People. Int J Environ Res Public Health. 2019;16(12).

14. NRCWE. Work Environment \& Health in Denmark [Internet]. National Research Centre for the Working Environment (NRCWE); 2018 [cited 2019 Sep 29]. Available from https://arbejdsmiljodata.nfa.dk/

15. Jakobsen MD, Sundstrup E, Brandt M, Persson R, Andersen LL. Estimation of physical workload of the low-back based on exposure variation analysis during a full working day among male blue-collar workers. Cross-sectional workplace study. Appl Ergon. 2018;70:127-33.

16. Wai EK, Roffey DM, Bishop P, Kwon BK, Dagenais S. Causal assessment of occupational lifting and low back pain: results of a systematic review. Spine J. 2010;10(6):554-66. 
17. Hauke A, Flintrop J, Brun E, Rugulies R. The impact of work-related psychosocial stressors on the onset of musculoskeletal disorders in specific body regions: a review and meta-analysis of 54 longitudinal studies. Work Stress. 2011;25(3):243-56.

18. Clausen T, Andersen LL, Holtermann A, Jorgensen AFB, Aust B, Rugulies R. Do self-reported psychosocial working conditions predict low back pain after adjustment for both physical work load and depressive symptoms? A prospective study among female eldercare workers. Occup Environ Med. 2013;70(8):538-44.

19. Foss L, Gravseth HM, Kristensen P, Claussen B, Mehlum IS, Knardahl S, et al. The impact of workplace risk factors on long-term musculoskeletal sickness absence: a registry-based 5-year follow-up from the Oslo health study. J Occup Environ Med. 2011;53(12):1478-82.

20. Mayer J, Kraus T, Ochsmann E. Longitudinal evidence for the association between work-related physical exposures and neck and/or shoulder complaints: a systematic review. Int Arch Occup Environ Health. 2012;85(6): 587-603.

21. Andersen LL, Fallentin N, Ajslev JZN, Jakobsen MD, Sundstrup E. Association between occupational lifting and day-to-day change in low-back pain intensity based on company records and text messages. Scand J Work Environ Health. 2017;43(1):68-74.

22. Clausen T, Madsen IE, Christensen KB, Bjorner JB, Poulsen OM, Maltesen T, et al. The Danish psychosocial work environment questionnaire (DPQ) development, content, reliability and validity. Scand J Work Environ Health. 2019:45(4):356-69.

23. Waddell G, Newton M, Henderson I, Somerville D, Main CJ. A fear-avoidance beliefs questionnaire (FABQ) and the role of fear-avoidance beliefs in chronic low back pain and disability. Pain. 1993;52(2):157-68.

24. Andersen LL, Andersen CH, Sundstrup E, Jakobsen MD, Mortensen OS, Zebis MK Central adaptation of pain perception in response to rehabilitation of musculoskeletal pain: randomized controlled trial. Pain Physician. 2012;15(5):385-94.

25. Jakobsen MD, Sundstrup E, Brandt M, Andersen LL. Effect of physical exercise on musculoskeletal pain in multiple body regions among healthcare workers: secondary analysis of a cluster randomized controlled trial. Musculoskelet Sci Pract. 2018;34:89-96.

26. Persson AL, Brogårdh C, Sjölund BH. Tender or not tender: test-retest repeatability of pressure pain thresholds in the trapezius and deltoid muscles of healthy women. J Rehabil Med. 2004;36(1):17-27.

27. Ylinen J, Nykänen $M$, Kautiainen $H$, Häkkinen A. Evaluation of repeatability of pressure algometry on the neck muscles for clinical use. Man Ther. 2007; 12(2):192-7.

28. Paungmali A, Sitilertpisan P, Taneyhill K, Pirunsan U, Uthaikhup S. Intrarater reliability of pain intensity, tissue blood flow, thermal pain threshold, pressure pain threshold and lumbo-pelvic stability tests in subjects with low back pain. Asian J Sports Med. 2012;3(1):8-14.

29. Balaguier R, Madeleine $P$, Vuillerme N. Intra-session absolute and relative reliability of pressure pain thresholds in the low back region of vine-workers: ffect of the number of trials. BMC Musculoskelet Disord. 2016;17(1):350.

30. Fleckenstein J, Simon P, König M, Vogt L, Banzer W. The pain threshold of high-threshold mechanosensitive receptors subsequent to maximal eccentric exercise is a potential marker in the prediction of DOMS associated impairment. PLoS One. 2017;12(10):e0185463.

31. Cheatham SW, Kolber MJ, Mokha GM, Hanney WJ. Concurrent validation of a pressure pain threshold scale for individuals with myofascial pain syndrome and fibromyalgia. J Man Manip Ther. 2018;26(1):25-35.

32. Jakobsen MD, Sundstrup E, Brandt M, Jay K, Aagaard P, Andersen LL. Physical exercise at the workplace reduces perceived physical exertion during healthcare work: cluster randomized controlled trial. Scand J Public Health. 2015;43(7):713-20.

33. Sundstrup E, Jakobsen MD, Brandt M, Jay K, Aagaard P, Andersen LL. Strength training improves fatigue resistance and self-rated health in workers with chronic pain: a randomized controlled trial. Biomed Res Int. 2016;2016:4137918.

34. Brandt M, Madeleine P, Samani A, Ajslev JZ, Jakobsen MD, Sundstrup E, et al. Effects of a Participatory Ergonomics Intervention With Wearable Technical Measurements of Physical Workload in the Construction Industry: Cluster Randomized Controlled Trial. J Med Int Res. 2018;20(12):e10272.

\section{Publisher's Note}

Springer Nature remains neutral with regard to jurisdictional claims in published maps and institutional affiliations.

\section{Ready to submit your research? Choose BMC and benefit from:}

- fast, convenient online submission

- thorough peer review by experienced researchers in your field

- rapid publication on acceptance

- support for research data, including large and complex data types

- gold Open Access which fosters wider collaboration and increased citations

- maximum visibility for your research: over $100 \mathrm{M}$ website views per year

At BMC, research is always in progress.

Learn more biomedcentral.com/submissions 